\title{
MOBILIDADE PENDULAR E MIGRAÇ̃̃O NA METRÓPOLE: PROPOSTA METODOLÓGICA APLICADA À REGIÃO METROPOLITANA DE BELO HORIZONTE
}

\author{
Pontifícia Universidade Católica de Minas Gerais, Programa de Pós-Graduação em Geografia \\ Belo Horizonte, MG, Brasil \\ gabriela.lima.diniz@gmail.com
}

Ana Márcia Moreira Alvim Pontifícia Universidade Católica de Minas Gerais, Programa de Pós-Graduação em Geografia, Belo Horizonte, MG, Brasil

\section{RESUMO} ammalvim@gmail.com

\begin{abstract}
O objetivo deste artigo consiste em propor uma metodologia para análise conjunta dos movimentos pendulares e migratórios, proposta que será aplicada para a compreensão destes fenômenos na Região Metropolitana de Belo Horizonte (RMBH). As informações necessárias foram obtidas na base de dados da Amostra do Censo Demográfico do Instituto Brasileiro de Geografia e Estatística (IBGE) de 2010. A produção de mapas valeu-se das bases cartográficas reunidas na biblioteca do Plano Metropolitano da RMBH. Em análise preliminar observou-se: que na $\mathrm{RMBH} 34,56 \%$ dos migrantes de última etapa faziam movimentos pendulares por motivo de trabalho e destes $65,6 \%$ tinham como destino preferencial o local de residência anterior; e que enquanto os movimentos pendulares tendem a ocorrer em um fluxo periferia-centro-periferia, os migratórios no âmbito metropolitano tendem ocorrer em um fluxo centro-periferia.
\end{abstract}

Palavras-chave: Movimentos pendulares. Movimentos migratórios. Região metropolitana de Belo Horizonte.

\section{COMMUTING AND MIGRATION IN THE METROPOLIS: METHODOLOGICAL PROPOSAL APPLIED TO METROPOLITAN REGION OF BELO HORIZONTE} \begin{abstract}
The aim of this article is to propose a methodology for joint analysis of commuting and migratory movements, a proposal that will be applied to understand these phenomena in the Metropolitan Region of Belo Horizonte (RMBH). The necessary information was obtained from the database from the 2010 Demographic Census Sample of the Brazilian Institute of Geography and Statistics (IBGE). In a preliminary analysis, it was observed that: in the RMBH, $34.56 \%$ of last-stage migrants made commuting for work reasons and of these $65.6 \%$ had their previous destination as their preferred destination; and that while pendulum movements tend to occur in a periphery-center-periphery flow, migratory movements in the metropolitan scope tend to occur in a center-periphery flow.
\end{abstract}

Keywords: Commuting. Migration. Metropolitan Region of Belo Horizonte.

\section{INTRODUÇÃO}

Por um longo período o interesse dos estudiosos da mobilidade espacial se voltava para as migrações, sobretudo, as de longas distâncias; entendendo-se como migrações os deslocamentos que implicam na mudança de residência de indivíduos, entre áreas que apresentam seus respectivos limites administrativos (DINIZ; ALVIM, 2019).

No entanto, recentemente, os esforços de pesquisa no campo da mobilidade urbana analisam os movimentos pendulares, que dizem respeito à saída e retorno diário do lugar de moradia para o lugar de trabalho ou estudo havendo transposição das fronteiras municipais temporariamente. (MOURA; CASTELLO BRANCO; FIRKOWSKI, 2005; PINHO; ROCHA; BRITO, 2014). Em áreas metropolitanas, onde as paisagens são tomadas pela conurbação ${ }^{1}$, estes dois movimentos - migração e pendularidade - estão cada vez mais relacionados, valendo à pena tratá-los conjuntamente para a análise da mobilidade espacial.

Desta maneira, a migração, assim como colocado por Cunha (2012), ainda que consista em mudança de residência, não necessariamente resulta em mudanças de espaço de vida. Já a pendulariade, como expresso por Ojima e Marandola Jr. (2012) "é equivalente ao conceito "commuting" que se refere aos

\footnotetext{
${ }^{1} \mathrm{O}$ termo conurbação refere-se ao processo de expansão urbana de uma cidade até seu limite municipal, sendo assim, em continuidade a seu tecido urbano, o município vizinho é ocupado como se fosse um prolongamento da cidade maior/principal (VILLAÇA, 1998).

Caminhos de Geografia U Uberlândia $\quad$ v. 22, n. $84 \quad$ dez/2021 $\quad$ p. 154-168 Página 154
}


deslocamentos da população entre local de residência e demais atividades cotidianas, principalmente para trabalho" (OJIMA; MARANDOLA JR., 2012, p.106). Por conseguinte, a mobilidade pendular "seria uma das faces mais visíveis deste processo: muda-se de lugar, mas não se perde o vínculo preexistente com o território" (CUNHA, 2012, p.34).

Para além das questões da mobilidade, faz-se necessário introduzir alguns conceitos relativos à desconcentração urbana para esclarecer o contexto da metrópole mineira. Gottidiener (1993) traz importantes contribuições para a compreensão dos espaços metropolitanos. O sociólogo sugere que há tempos uma nova forma de organização socioespacial vem se consolidando, em que o espaço urbano não deve mais ser compreendido como sinônimo de cidades centrais as quais findam em si mesmas. Propõe então a ideia de "região metropolitana polinucleada". Tal reconceituação é relacionada às múltiplas funções assumidas pelo espaço metropolitano. Para o autor, as áreas urbanizadas, sobretudo aquelas que circundam as cidades maiores, deveriam ser compreendidas como cidades multimodais. Dito isto, a polinucleação seria uma consequência ao crescimento populacional das cidades que circundam municípios de maior porte o terreno físico (como possibilidade de expansão), a dimensão da própria metrópole, o vigor da economia regional e a rede de transportes (GOTTIDIENER, 1993, p.17). Estas características produziriam então, modificações tanto no modo de vida, quanto no modo de organização social dos ambientes urbanos. Tais modificações seriam fruto do que Gottidiener (1993) denomina por desconcentração:

Desconcentração se refere ao aumento absoluto de população e à densidade de atividades sociais em áreas fora das tradicionais regiões citadinas e dos centros populacionais. [...] Além disso, nessa visão o processo de desconcentração implica tanto um movimento socioeconômico que sai das cidades centrais mais antigas para áreas mais afastadas - ou descentralização - quanto o surgimento de aglomerações tipo cidade e a formação de densidade social em áreas afastadas - ou concentração. (GOTTIDIENER, 1993, p.19).

Para o autor a desconcentração em regiões fruto do capitalismo tardio implica no crescimento suburbano, ou seja, fora do centro de concentração econômica, produzindo-se então uma diferenciação funcional relacionada à divisão do trabalho. Ademais tal diferenciação produz efeitos no ordenamento territorial das áreas.

Tabela 1 - Taxa média geométrica de crescimento anual (\%) da população residente, em Belo Horizonte, na RMBH e na RMBH exclusive Belo Horizonte nos períodos entre 1970/1980, $1980 / 1991$ e $2000 / 2010$

\begin{tabular}{lcccc}
\hline Unidade territorial & $\mathbf{1 9 7 0 / 1 9 8 0}$ & $\mathbf{1 9 8 0 / 1 9 9 1}$ & $\mathbf{1 9 9 1 / 2 0 0 0}$ & $\mathbf{2 0 0 0 / 2 0 1 0}$ \\
\hline $\mathrm{BH}$ & 3,73 & 1,41 & 1,15 & 0,59 \\
$\mathrm{RMBH}$ & 4,51 & 3,08 & 2,39 & 1,15 \\
$\mathrm{RMBH}$ exclusive BH & 6,28 & 5,85 & 3,89 & 1,7 \\
\hline
\end{tabular}

Fonte: Elaboração própria. Amostra do Censo Demográfico 2010

Dado este preâmbulo, pode-se dizer que desconcentração é o que verifica-se na Região Metropolitana de Belo Horizonte $(\mathrm{RMBH})$ onde a taxa média geométrica de crescimento anual da população intrametropolitana do período de sua origem na década de 1970, até o período do último Censo disponível, de 2010. De acordo com a Tabela 1, tem- se que o ritmo de crescimento da Região Metropolitana com a participação de todos os municípios vem diminuindo com o tempo. Em contrapartida, quando comparadas as taxas médias geométrica de crescimento anual de Belo Horizonte, com as mesmas taxas da RMBH com e sem a participação de Belo Horizonte, o que ocorre é o aumento significativo destas. Com isto, é possível apontar que a RMBH tende a se expandir rumo aos municípios periféricos, fato que já vem ocorrendo desde a sua criação, 1970/1980 (Tabela 1 e Gráfico 1).

Gráfico 1 - Taxa média geométrica de crescimento anual (\%) da população residente, em Belo Horizonte, na RMBH e na RMBH exclusive Belo Horizonte nos períodos entre 1970/1980, $1980 / 1991$ e $2000 / 2010$ 


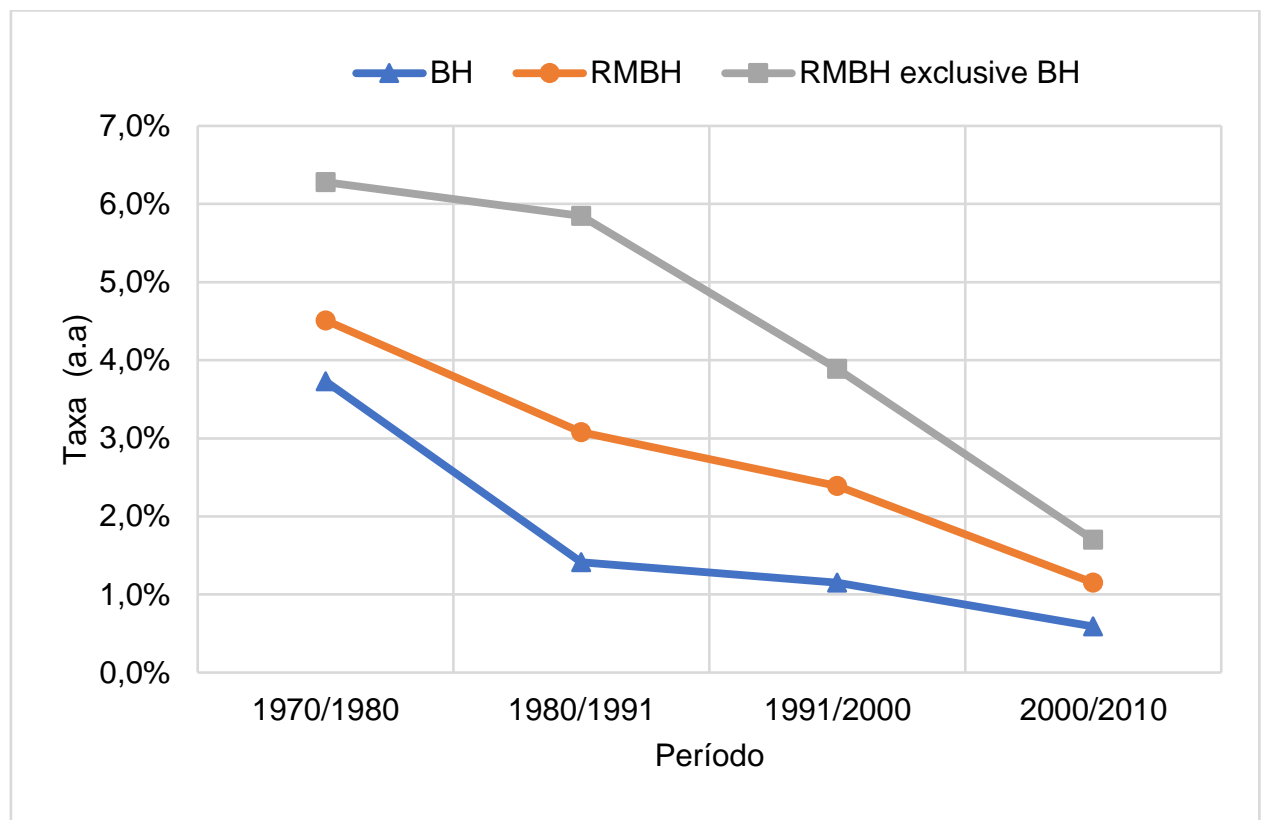

Fonte: Elaboração própria. Amostra do Censo Demográfico

Em relação à população, durante o período de 1970/1980 nove municípios ficaram abaixo da média metropolitana (4,51\%a.a.). O município de Ribeirão das Neves se destacou apresentando um ritmo de crescimento populacional muito alto de $21,36 \%$ a.a., o mais elevado durante todos os períodos que se seguiram, já configurando-se como cidade-dormitório. O termo cidade-dormitório é empregado para referirse à cidade procurada por indivíduos como local de moradia, mas não como local de trabalho e/ou estudo. Esse tipo de cidade se consolida pelo crescimento demográfico através da migração e sua população realiza movimento pendular cotidianamente (OJIMA et al 2011).

No período de 1980/1991, 15 municípios apresentaram taxas médias geométricas de crescimento anual acima da média metropolitana (3,0\% a.a.) e lbirité foi o município que apresentou a maior taxa, $9,8 \%$. No período de 1991/2000 houve uma queda em relação ao período anterior do número de municípios que apresentaram taxas médias geométricas de crescimento anual mais elevadas do que a média metropolitana (2,39\% a. a), sendo que a taxa mais alta foi a do município de Esmeraldas. Entre 2000/2010 aumentou significativamente o número de municípios que tiveram a taxa média de crescimento geométrico maior do que a média metropolitana $(1,15 \%$ a.a.), somando-se 24 municípios. E durante este período (2000/2010), a maior taxa foi calculada para o município de Sarzedo, 4,1\% a.a.

Dessa forma, é possível delinear que o crescimento populacional da RMBH tende a influenciar a expansão metropolitana, seguindo uma divisão espacial demarcada principalmente pela BR-381, que coincide com as áreas com topografia mais plana e com espaço disponível. Assim, tem-se que a expansão tomando como referência a BR-381 segue as direções nordeste, noroeste e sudoeste (ver Figura 1).

Dado que no contexto metropolitano polinucleado, a mobilidade espacial torna-se cada vez mais intensa, estando as migrações e os movimentos pendulares diretamente associados, o que gera desdobramentos técnicos administrativos não somente para os municípios, mas também para as próprias regiões metropolitanas.

Vale esclarecer que até o ano de 2000 o Instituto Brasileiro de Geografia e Estatística (IBGE), a variável referente aos movimentos pendulares referia-se aos deslocamentos para trabalho e estudo de modo conjunto, para cada município. Em 2010 foi cedido pelo IBGE dados para trabalho e estudo separadamente, uma vez que no questionário da amostra foi incluída uma pergunta sobre o retorno diário da população ocupada do local de trabalho para o local de residência. Por tudo isso tem-se como objetivo realizar uma proposta metodológica para análise espacial dos deslocamentos pendulares e migratórios intermunicipais de forma conjunta no âmbito metropolitano. Proposta aplicada neste artigo à RMBH (Figura 1) com o uso de dados demográficos. 
Figura 1 - Região Metropolitana de Belo Horizonte (MG): Sedes municipais, eixos rodoviários e mancha urbana.

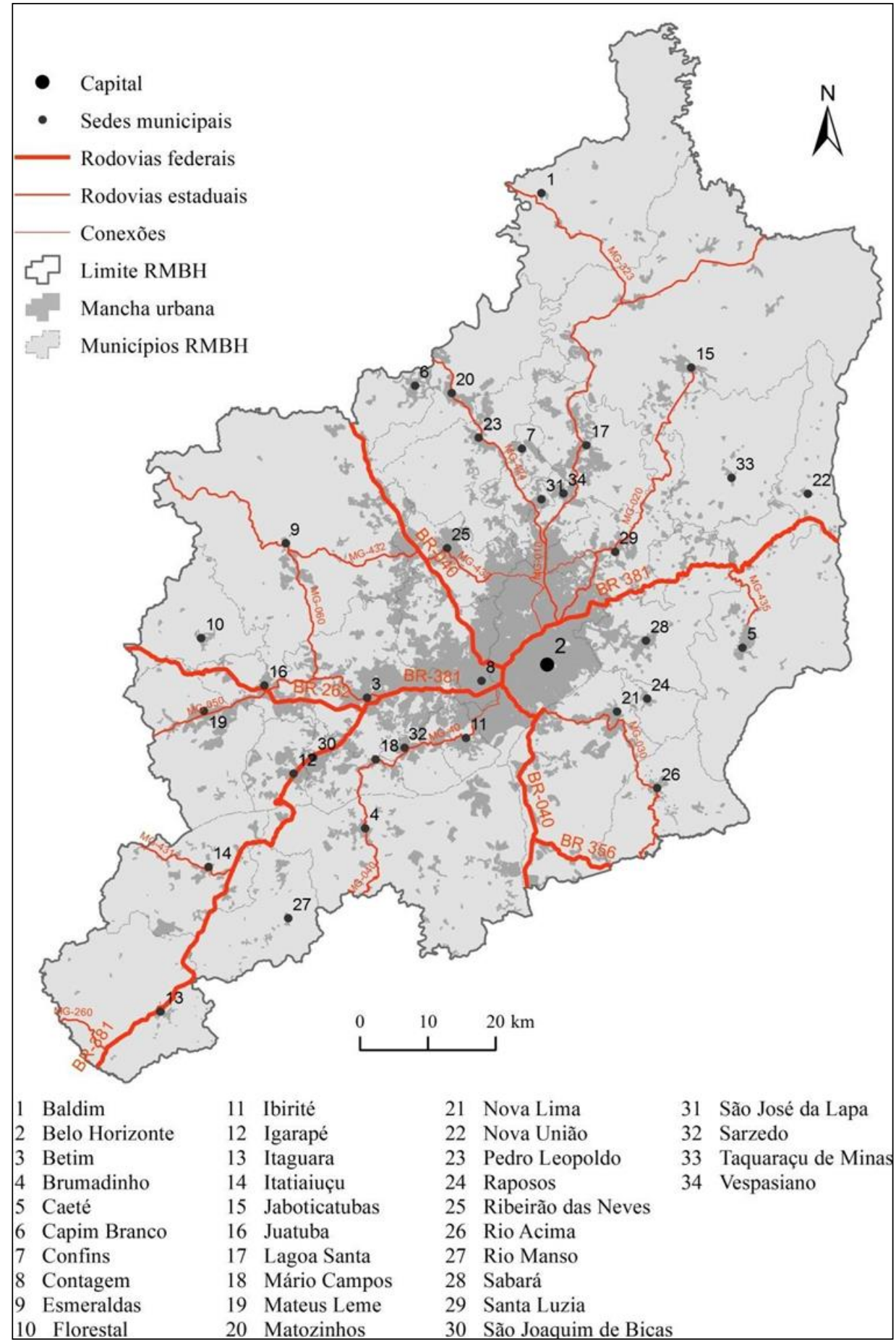

Fonte: Elaboração própria. Amostra do Censo Demográfico 2010; DNIT. 
Figura 3 - Organograma metodológico de coleta e tratamento dos dados

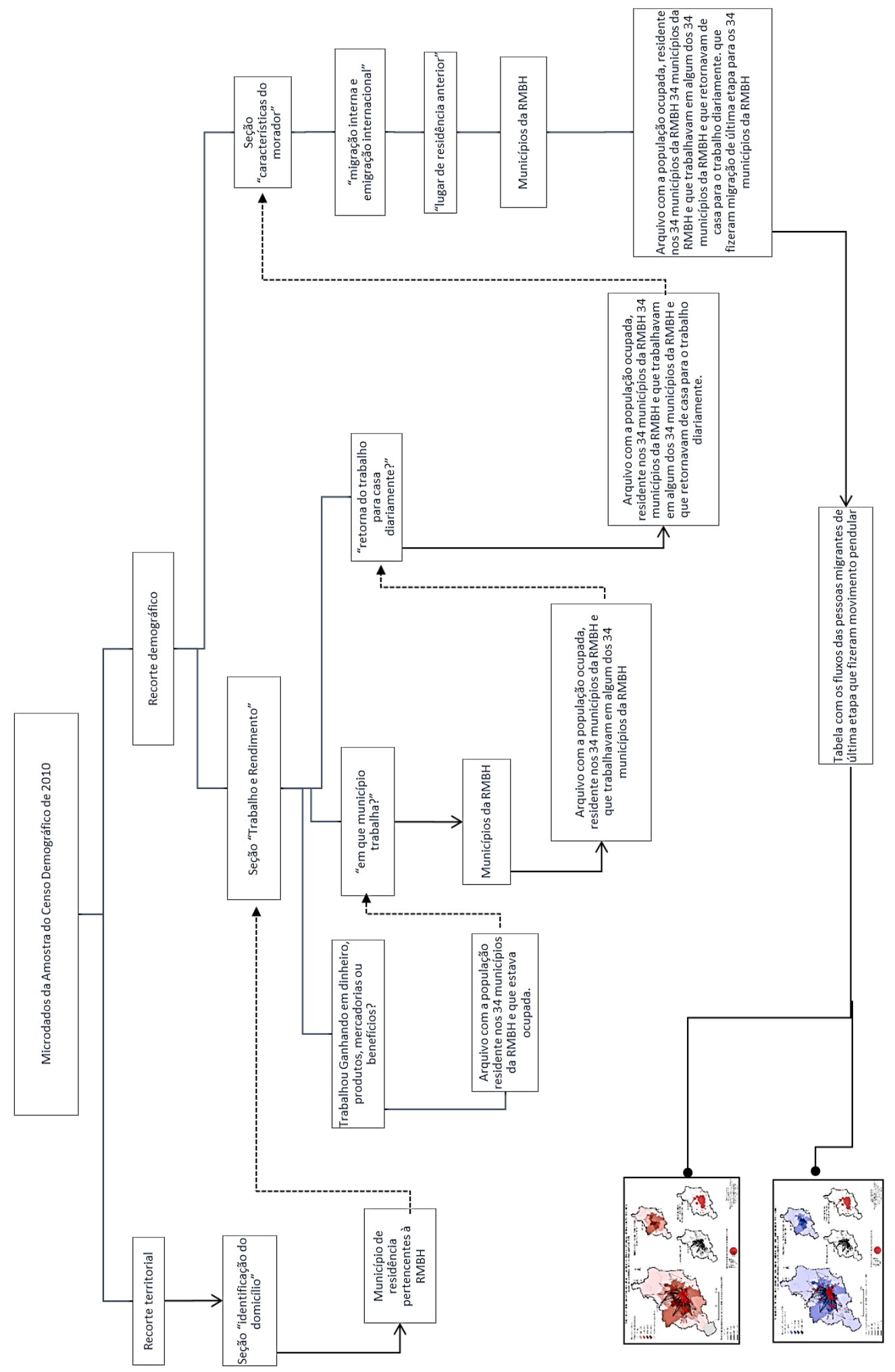

Fonte: Elaboração própria. Questionário da Amostra, IBGE 2010 
Quadro 1 - Descrição das variáveis - Microdados da amostra do Censo Demográfico 2010

\begin{tabular}{|c|c|c|c|}
\hline \multicolumn{4}{|c|}{ Recorte territorial } \\
\hline Variável & Descrição & Definição & Filtro \\
\hline V0002 & Município de residência & $\begin{array}{l}\text { Retorna como resultado o } \\
\text { código do município de } \\
\text { residência }\end{array}$ & $\begin{array}{l}\text { Residir em um dos } \\
34 \text { municípios da } \\
\text { RMBH }\end{array}$ \\
\hline \multicolumn{4}{|c|}{ Recorte demográfico } \\
\hline Variável & Definição & Descrição & Filtro \\
\hline V0641 & $\begin{array}{l}\text { População com dez anos } \\
\text { ou mais ocupada na } \\
\text { semana de referência }\end{array}$ & $\begin{array}{l}\text { Indica a população com dez } \\
\text { anos ou mais que que exerceu } \\
\text { algum trabalho durante pelo } \\
\text { menos uma hora completa na } \\
\text { semana de referência. Retorna } \\
1 \text { para população ocupada, } 2 \\
\text { para não ocupada e branco } \\
\text { para a população que não } \\
\text { segue os critérios ou não } \\
\text { respondeu. }\end{array}$ & $\begin{array}{l}\text { Estar ocupado na } \\
\text { semana de } \\
\text { referência. }\end{array}$ \\
\hline V6254 & $\begin{array}{l}\text { Município de residência } \\
\text { anterior (migração de } \\
\text { última etapa) }\end{array}$ & $\begin{array}{l}\text { Indica o último lugar de moradia } \\
\text { anterior do indivíduo, sem } \\
\text { interrupções há menos de dez } \\
\text { anos. }\end{array}$ & $\begin{array}{l}\text { Residiu } \\
\text { anteriormente em } \\
\text { um dos } 34 \\
\text { municípios da } \\
\text { RMBH }\end{array}$ \\
\hline V6604 & Município que trabalhava & $\begin{array}{l}\text { Retorna como resultado o } \\
\text { código do município onde } \\
\text { trabalhava. }\end{array}$ & $\begin{array}{l}\text { Trabalhar em um } \\
\text { dos } 34 \text { municípios } \\
\text { da RMBH. }\end{array}$ \\
\hline V0661 & $\begin{array}{l}\text { Retorna do trabalho para } \\
\text { casa diariamente } \\
\text { (pendularidade) }\end{array}$ & $\begin{array}{l}\text { Variável de deslocamento para } \\
\text { o trabalho. O objetivo deste } \\
\text { quesito era separar as pessoas } \\
\text { que efetivamente realizavam } \\
\text { deslocamento diário de casa } \\
\text { para o trabalho daquelas que, } \\
\text { por exemplo, permaneciam no } \\
\text { trabalho ou em outro município } \\
\text { durante a semana e retornavam } \\
\text { para casa apenas no fim de } \\
\text { semana. Retorna como } \\
\text { resultado o número } 1 \text { (sim) para } \\
\text { quem declarou retornar } \\
\text { diariamente do trabalho para } \\
\text { casa ou o número } 2 \text { (não) para } \\
\text { quem não retorna diariamente } \\
\text { do trabalho para casa. }\end{array}$ & $\begin{array}{l}\text { Retornar } \\
\text { diariamente do local } \\
\text { de trabalho para o } \\
\text { local de residência }\end{array}$ \\
\hline
\end{tabular}

Fonte: Elaboração própria. Questionário da Amostra, IBGE 2010 
As informações referentes à mobilidade pendular e migração foram extraídas conforme a seleção de itens organizados nas seções "identificação do domicílio", "características do morador", "migração interna e emigração internacional" e "deslocamento para o trabalho". Para chegar à população migrante de última etapa que fez deslocamento pendular por motivo de trabalho na RMBH (Quadro 1 e Figura 3) seguiu-se as seguintes etapas, utilizando-se de ferramentas de seleção e tabulações cruzadas disponíveis no software IBM SPSS Statistics 22:

a. Inicialmente, na seção "Identificação do domicílio" foi selecionada a variável V0002 (Quadro 1) e feito o filtro dos que residiam (origem) nos trinta e quatro municípios integrantes da região metropolitana de Belo Horizonte;

b. Da seção "Trabalho e Rendimento" foram selecionadas as pessoas ocupadas na semana de referência, a variável V0641, segundo a subseção "divisão e classe de atividade do trabalho principal". Conforme classificação do IBGE essa população é correspondente à População Economicamente Ativa (PEA), que indica o a população ocupada com 10 anos e mais de idade;

c. Depois, da seção "deslocamento para o trabalho" foi escolhida a variável de local de trabalho anunciada na pergunta "em que município e unidade da federação ou país estrangeiro trabalha?". A partir desta pergunta foram selecionados os indivíduos que responderam "em outro município". Ou seja, o município de trabalho desta população, indicado pela variável V6604;

d. E, também da seção "deslocamento para o trabalho", para caracterizar o movimento pendular foram agrupadas as informações apenas daqueles indivíduos que responderam "sim" à pergunta "retorna do trabalho para casa diariamente?", variável V0661.

e. Por fim como último passo da seleção, da seção "migração interna e imigração internacional" foi eleita a variável "lugar de residência anterior", variável V6254, indicando o último lugar de moradia anterior do indivíduo, sem interrupções há menos de dez anos.

Dessa maneira, os microdados da amostra, permitiram agrupar as informações da população dos trinta e quatro municípios constituintes da RMBH, que residia anteriormente em outros municípios da RMBH há pelo menos dez anos e que trabalhava na $\mathrm{RMBH}$ e retornava diariamente para o seu local de residência. $\mathrm{O}$ tratamento dos microdados possibilitou o mapeamento destes fluxos, através do uso de Sistema de Informação Geográfica (SIG).

No intuito de melhor compreender a mobilidade espacial na RMBH e, logo, seu processo de metropolização, foram considerados os fluxos populacionais, seja sob a forma de pendularidade, seja sob a forma de migração. Para analisar a migração de última etapa ocorrida desta região metropolitana entre os anos 20002010, procurou-se identificar os municípios que mais expulsaram e os que mais atraíram migrantes no âmbito intrametropolitano. Em seguida, investigou-se a pendularidade por motivo de trabalho ocorrida entre esses municípios em 2010. Isso associando os dois processos, identificando e mapeando os migrantes de última etapa (período de 2000 a 2010) que fizeram o movimento pendular por motivo de trabalho em 2010.

Para tanto, os dados foram agregados em colunas a partir do comando agregate do SPSS 22, tendo sido geradas quatro colunas contendo as informações de município de residência em de julho de 2010 (última etapa), município de residência na semana de referência do recenseamento, município onde trabalhava na semana de referência e o número de migrantes que fizeram pendularidade (ver exemplo na Tabela 2). Para a organização e a tabulação dos dados, utilizou-se o software Microsoft Office Excel 2016.

Tabela 2 - Exemplo de Tabela final

\begin{tabular}{llll}
\hline $\begin{array}{c}\text { Município de } \\
\text { residência anterior }\end{array}$ & \multicolumn{1}{c}{$\begin{array}{c}\text { Município } \\
\text { de residência }\end{array}$} & $\begin{array}{c}\text { Município de } \\
\text { trabalho }^{4}\end{array}$ & $\begin{array}{c}\text { Migrantes } \\
\text { pendulares }^{5}\end{array}$ \\
\hline Belo Horizonte & Ribeirão das Neves & Belo Horizonte & 10.286 \\
Belo Horizonte & Contagem & Belo Horizonte & 8.816 \\
Belo Horizonte & Santa Luzia & Belo Horizonte & 4.527 \\
Belo Horizonte & lbirité & Belo Horizonte & 4.132 \\
Belo Horizonte & Vespasiano & Belo Horizonte & 4.022 \\
\hline
\end{tabular}

Fonte: Elaboração própria. Questionário da Amostra, IBGE 2010

\footnotetext{
${ }^{3}$ Último município de residência nos períodos intercensitários, 2000 e 2010.

${ }^{4}$ Município de residência em 31 de julho de 2010, data de referência do Censo.

${ }^{5}$ Essa categoria se refere às pessoas ocupadas, que moravam em $\mathrm{BH}$ e se mudaram para outros municípios dentro da RMBH nos últimos 10 anos e que realizavam pendularidade por motivo trabalho.

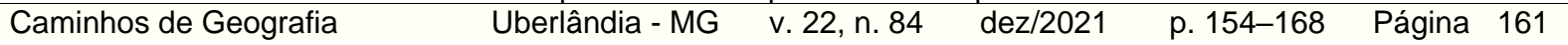


Para a confecção dos mapas foi utilizado o ArcGIS versão 10.3 e na padronização das legendas foi aplicado o método natural breaks (quebra natural), o qual determina o melhor arranjo de valores em diferentes classes, através da redução da variação dentro de cada classe e da maximização da variância entre as classes. Para os mapas coropléticos, aqueles que expressam os fenômenos através da intensidade das cores, optou-se pelo agrupamento com cinco classes de valores obtidos, ora com seis. Nos mapas as classes em tons de vermelho representam o poder de atração (imigração) e em tons de azul representam o poder de expulsão (emigração).

Para representar as informações referentes à migração de última etapa e pendularidade por motivo de trabalho de forma associada, foram elaborados dois mapas síntese. Nestes foram expressos os migrantes pendulares por cores, em vermelho os imigrantes pendulares (Figura 4), e em azul os emigrantes pendulares (Figura 5); os fluxos e as chegadas de pendulares foram representados, respectivamente por linhas e círculos proporcionais.

Por meio do tratamento dos dados censitários do Censo Demográfico do IBGE em 2010 (que utiliza a CBOdomiciliar) buscou-se identificar os grupos ocupacionais dos migrantes pendulares na RMBH. Mas como os dados ocupacionais são fornecidos com tamanho nível de detalhamento, contabilizando-se 2.614 ocupações, decidiu-se agrupá-los conforme os grandes grupos de ocupações da Classificação Brasileira de Ocupações $(\mathrm{CBO})^{6}$ quais são: Forças Armadas, Policiais e Bombeiros Militares; Membros superiores do poder público, dirigentes de organizações de interesse público e de empresas e gerentes; Profissionais das ciências e das artes; Técnicos de nível médio; Trabalhadores de serviços administrativos; Trabalhadores dos serviços, vendedores do comércio em lojas e mercados; Trabalhadores agropecuários, florestais, da caça e pesca; Trabalhadores da produção de bens e serviços industriais; Trabalhadores da produção de bens e serviços industriais - sistemas de produção; Trabalhadores de manutenção e reparação.(CBO, 2020)

\section{RESULTADOS E DISCUSSÃO}

Em 2010, foram contabilizados 81.455 migrantes que realizaram pendularidade na RMBH (Tabela 2). Destes, 54.165 mantiveram vínculo com o local de residência anterior, o que representa $65,6 \%$ do total da população de emigrantes pendulares, mostrando assim a dissociação residencial desta população migrante em relação ao local de trabalho. A partir desta informação, pode-se explorar algumas possibilidades de análise.

A relação de expulsão e manutenção de vínculo para trabalho mostrou-se mais expressiva entre os municípios conurbados (Figura ) e (). Dentre os resultados obtidos, destaca-se Belo Horizonte como o município que mais expulsou população para residir em outros municípios da RMBH. Ao todo expulsou 53.298 migrantes que correspondem a 65,4\% da população que fez migração entre 2000 e 2010 na RM e que realizou o movimento pendular em 2010 tendo Belo Horizonte como local de residência anterior. Por outro lado, Belo Horizonte também foi o município da RMBH que mais recebeu migrantes pendulares por motivo de trabalho, pois $72,9 \%$ dos que migraram entre 2000 e 2010 na RM trabalhavam em 2010 em Belo Horizonte. Destes, a maioria manteve vínculo de trabalho com a capital $(56,0 \%)$. No período analisado, também é expressiva a quantidade de pessoas que saíram de Belo Horizonte para residir em Ribeirão das Neves, e que por sua vez fizeram a pendularidade em 2010 para Belo Horizonte (10.286, que representa $12,6 \%$ do total de migrantes pendulares no âmbito intrametropolitano (Tabela 2).

Este resultado expõe algumas tendências e permanências relacionadas ao histórico da RMBH. Como permanência pode-se afirmar que os eixos de crescimento permanecem majoritariamente, em termos de proporções, na direção oeste no eixo industrial, e na direção norte. Destaca-se a manutenção do "município de Ribeirão das Neves como dormitório já que o município era, de 2000 a 2010, o local de moradia de 18,6\% da população migrante pendular. Também é expressiva a relação entre Belo Horizonte e Ribeirão das Neves, pois grande parcela da população que residia no município de Ribeirão das Neves teve Belo Horizonte como local de moradia anterior, e de acordo com os resultados estas mesmas pessoas continuaram tendo Belo Horizonte como local de trabalho, fazendo assim o movimento pendular. Dito isto, pode-se afirmar que ambos os municípios mantêm uma relação de interdependência, visto que Ribeirão

\footnotetext{
${ }^{6} \mathrm{~A}$ escolha de se analisar os dados de ocupação por meio da classificação da CBO ocorreu por ser disponível ao público e, além disso, por tratar-se de uma classificação que permite comparações com dados internacionais, já que sua organização segue normas e padrões estabelecidos pela Organização Internacional do Trabalho (OIT).
}

$\begin{array}{llllll}\text { Caminhos de Geografia } & \text { Uberlândia - MG } & \text { v. 22, n. } 84 & \text { dez/2021 } & \text { p. 154-168 } & \text { Página } 162\end{array}$


das Neves é o principal provedor de mão de obra para o município de Belo Horizonte, e que Belo Horizonte é o município que mais emprega/ocupa a população de Ribeirão das Neves.

Continuando este raciocínio, pode-se afirmar que a população ocupada de Ribeirão das Neves, em sua maioria, não consegue residir na capital devido aos altos valores dos aluguéis e dos terrenos em Belo Horizonte, chegando até a ocupar de forma irregular as margens das rodovias, a (BR 040 e a MG432). Tal fato se concretiza como uma barreira econômica, pois Ribeirão das Neves dispõe em grande proporção da sua população ocupada nos setores de comércio, reparação de veículos automotores e motocicletas $(19,2 \%)$; construção civil $(14,1 \%)$; e serviços domésticos, ou seja, elementares (10,8\%).

A relação entre Nova Lima e Belo Horizonte se dá tanto pelo fator da conurbação, quanto da oferta de moradias para população de alta renda. E como já foi explorado anteriormente por pesquisadores locais, Nova Lima está suscetível à formação de uma periferia, a qual reproduz as moradias do tipo condomínio fechado (SOARES DE MOURA COSTA et al., 2006; SOARES DE MOURA COSTA, [s.d.]).

A proximidade geográfica destes municípios e a presença de redes técnicas de articulação territorial, as rodovias e mesmo as vias, constituem elementos tão relevantes para a orientação destes fluxos quanto a disponibilidade de empregos em Belo Horizonte. Este resultado também reafirma a centralidade de Belo Horizonte em detrimento aos demais municípios da região.

Como já tem sido constatado por diversos autores, há no Brasil uma tendência ao decrescimento dos principais núcleos urbanos haja vista a desconcentração, dispersão, expansão, e processo de segregação socioespacial.(BRITO; SOUZA, 2005; CANETTIERI, 2015; LIMONAD; COSTA, 2015; LOBO et al., 2015). No caso da RMBH, averígua-se, portanto, a relação paradoxal entre a centralidade de Belo Horizonte e a descentralização residencial da capital. A assimetria dos usos e funções do espaço metropolitano da região é notável, pois mesmo existindo uma articulação espacial destes municípios com Belo Horizonte via acesso rodoviário, dada inclusive pela proximidade, o vínculo empregatício da população com a capital se mantém. Afinal, se por um lado há uma ruptura da população por ter se deslocado para morar na região circunvizinha da capital, há o deslocamento rumo a ela para se trabalhar.

Fica evidente que a população em questão, no quesito município de residência anterior (que residia no município até dez anos antes do recenseamento de 2010), se concentrava no polo, indicando um deslocamento clássico do tipo centro-periferia para fins de moradia e periferia-centro para fins de trabalho (ver Figura e ). Este dinamismo reforça a segregação residencial (distanciamento geográfico e social) na região e reafirma a problemática da distribuição fundiária no ambiente urbano, e mais recentemente, dos processos de rentismo em municípios de centro dinâmico (DINIZ, 2017). Enquanto os demais municípios, periféricos geograficamente e socialmente, não possuem um dinamismo econômico capaz de absorver esta população para fins de trabalho.

Por outro lado, apesar da predominância dos deslocamentos do tipo centro-periferia para morar e periferiacentro para trabalhar, a presença expressiva da população que residia nos municípios do vetor sul, como Nova Lima e Brumadinho (3,5\% dos migrantes pendulares), confronta-nos com a ideia de que a segregação residencial não se dá apenas em termos de favelização (formação de áreas aglutinadoras de população de baixa renda, moradias com baixos padrões construtivos ou conjuntos habitacionais). Afinal, o fenômeno da descentralização na RMBH é produtor de "novas periferias metropolitanas" (SOARES DE MOURA COSTA et al., 2006) no vetor sul, cuja população atraída para morar se difere em termos de padrão socioeconômico, o que fica nítido quando se vê o padrão construtivo na zona sul.

Os dados de migração permitem mensurar a atração e expulsão dos municípios no âmbito intrametropolitano, atração usualmente relacionada à condição do município perante os demais; afinal, normalmente o migrante procura municípios mais dinâmicos economicamente para morar, pois majoritariamente o migrante está em idade ativa e procura se inserir no mercado de trabalho com vistas à ascensão socioeconômica. (OJIMA; MARANDOLA JR; 2012)

Os dados de fluxos migratórios e pendulares permitem verificar o poder de atração e de expulsão dos municípios, pois as desigualdades e as funcionalidades destes têm o poder de aumentar ou diminuir a mobilidade intrametropolitana através das trocas populacionais. Embora essa variável seja de grande relevância, cabe lembrar que ela é altamente influenciável pelo volume populacional de cada município. 
Tabela 2 - Município de residência anterior, município de residência, município de trabalho e migrante que fez pendularidade na $\mathrm{RMBH}$, no ano de 2010

\begin{tabular}{|c|c|c|c|c|}
\hline $\begin{array}{c}\text { Município de } \\
\text { residência } \\
\text { Anterior } \\
\end{array}$ & $\begin{array}{l}\text { Município de } \\
\text { residência }\end{array}$ & $\begin{array}{l}\text { Município de } \\
\text { trabalho }\end{array}$ & $\begin{array}{c}\text { Migrantes } \\
\text { pendulares }\end{array}$ & $\begin{array}{c}\text { Migrantes } \\
\text { pendulares (\%) }\end{array}$ \\
\hline Belo Horizonte & $\begin{array}{c}\text { Ribeirão das } \\
\text { Neves }\end{array}$ & Belo Horizonte & 10.286 & 12,6 \\
\hline Belo Horizonte & Contagem & Belo Horizonte & 8.816 & 10,8 \\
\hline Belo Horizonte & Santa Luzia & Belo Horizonte & 4.527 & 5,6 \\
\hline Belo Horizonte & Ibirité & Belo Horizonte & 4.132 & 5,1 \\
\hline Belo Horizonte & Vespasiano & Belo Horizonte & 4.022 & 4,9 \\
\hline Belo Horizonte & Sabará & Belo Horizonte & 3.556 & 4,4 \\
\hline Belo Horizonte & Betim & Belo Horizonte & 2.419 & 3 \\
\hline Belo Horizonte & Nova Lima & Belo Horizonte & 2.416 & 3 \\
\hline Contagem & Betim & Contagem & 2.245 & 2,8 \\
\hline Belo Horizonte & Esmeraldas & Belo Horizonte & 1.402 & 1,7 \\
\hline Contagem & Betim & Belo Horizonte & 1.393 & 1,7 \\
\hline Belo Horizonte & Lagoa Santa & Belo Horizonte & 1.195 & 1,5 \\
\hline Contagem & $\begin{array}{c}\text { Ribeirão das } \\
\text { Neves }\end{array}$ & Belo Horizonte & 1.106 & 1,4 \\
\hline Contagem & Belo Horizonte & Contagem & 861 & 1,1 \\
\hline Belo Horizonte & Betim & Contagem & 841 & 1 \\
\hline Contagem & Ibirité & Belo Horizonte & 805 & 1 \\
\hline Belo Horizonte & Ibirité & Contagem & 723 & 0,9 \\
\hline Belo Horizonte & $\begin{array}{l}\text { Ribeirão das } \\
\text { Neves }\end{array}$ & Contagem & 718 & 0,9 \\
\hline Belo Horizonte & Sarzedo & Belo Horizonte & 692 & 0,8 \\
\hline Contagem & Esmeraldas & Contagem & 665 & 0,8 \\
\hline Belo Horizonte & Contagem & Betim & 645 & 0,8 \\
\hline Contagem & $\begin{array}{l}\text { Ribeirão das } \\
\text { Neves }\end{array}$ & Contagem & 590 & 0,7 \\
\hline Contagem & Ibirité & Contagem & 580 & 0,7 \\
\hline Betim & Contagem & Betim & 540 & 0,7 \\
\hline Santa Luzia & $\begin{array}{l}\text { Ribeirão das } \\
\text { Neves }\end{array}$ & Belo Horizonte & 519 & 0,6 \\
\hline Belo Horizonte & $\begin{array}{l}\text { São José da } \\
\text { Lapa }\end{array}$ & Belo Horizonte & 504 & 0,6 \\
\hline Betim & Contagem & Belo Horizonte & 499 & 0,6 \\
\hline $\begin{array}{l}\text { Ribeirão das } \\
\text { Neves }\end{array}$ & Vespasiano & Belo Horizonte & 472 & 0,6 \\
\hline Belo Horizonte & Ibirité & Betim & 411 & 0,5 \\
\hline Belo Horizonte & Brumadinho & Belo Horizonte & 379 & 0,5 \\
\hline Belo Horizonte & Esmeraldas & Contagem & 378 & 0,5 \\
\hline outros & outros & outros & 14565 & 28,2 \\
\hline total & - & - & 81455 & 100 \\
\hline
\end{tabular}

Fonte: Elaboração própria. Questionário da Amostra, IBGE 2010 
Figura 4 - Região Metropolitana de Belo Horizonte (MG): Imigrantes de última etapa intrametropolitanos que realizaram movimento pendular por motivo de trabalho na semana de referência do Censo de 2010

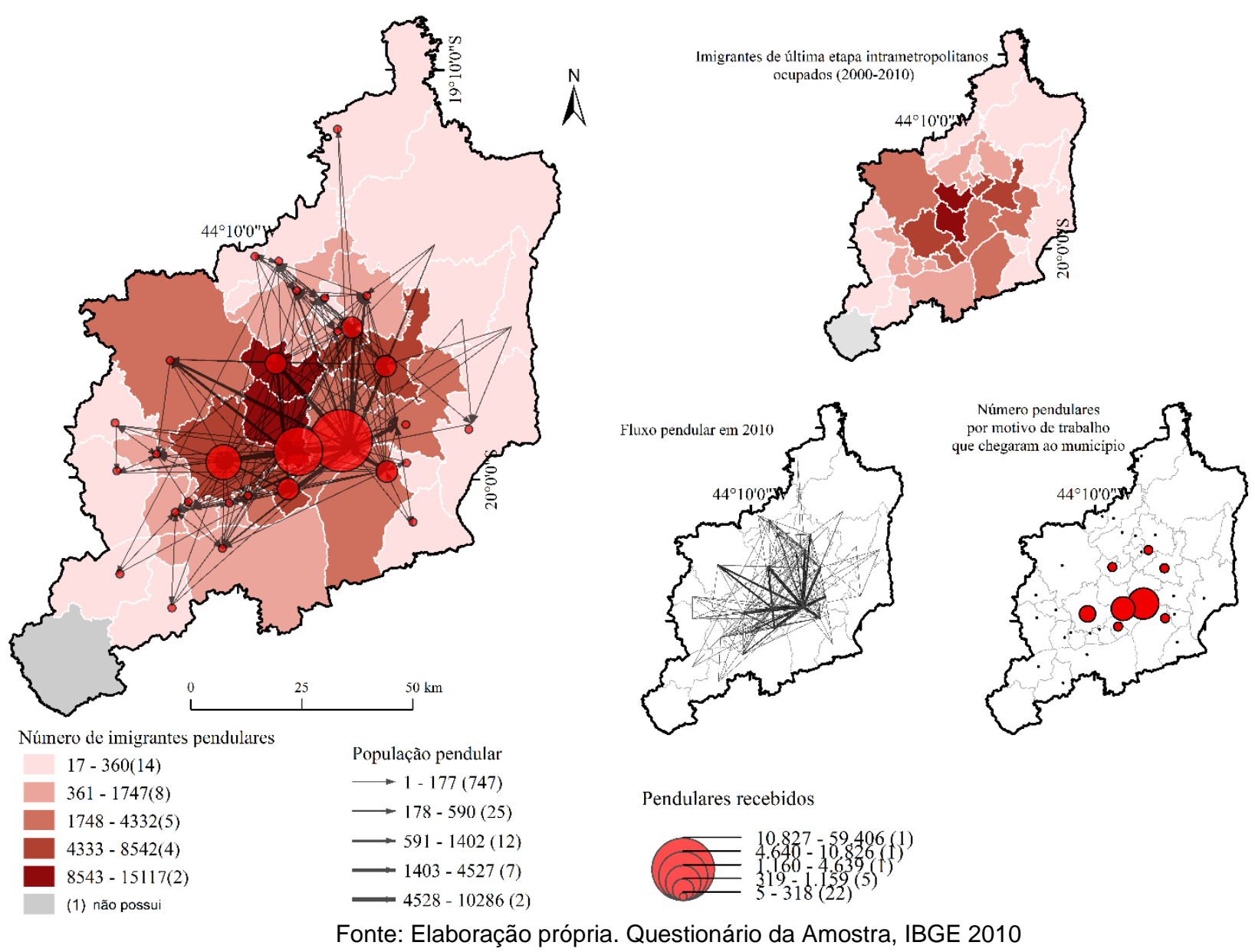


Figura 5 - Região Metropolitana de Belo Horizonte (MG): Emigrantes de última etapa intrametropolitanos que realizaram movimento pendular por motivo de trabalho na semana de referência do Censo de2010

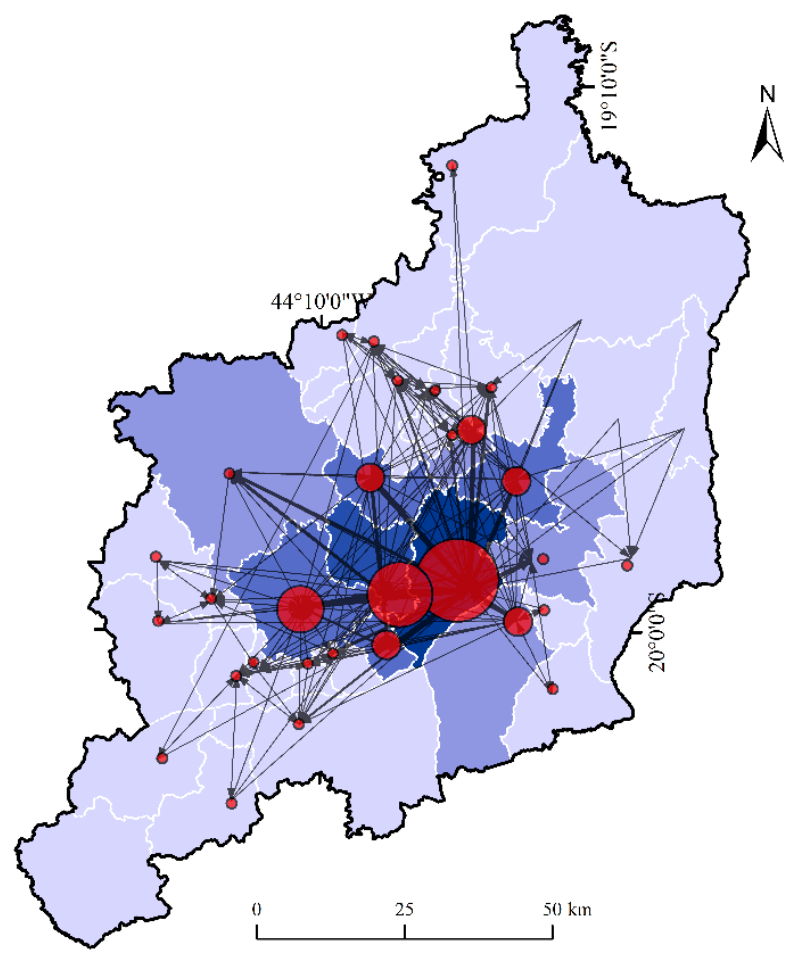

Número de emigrantes pendulares

$24-416(24)$

$417-1210(4)$

$1211-3540(4)$

$3541-11196(1)$

$11197-53298(1)$
População pendular

$\longrightarrow 1-177(747)$

$\longrightarrow 178-590(25)$

$\longrightarrow 591-1402(12)$

$-1403-4527(7)$

$4528-10286(2)$
$N$

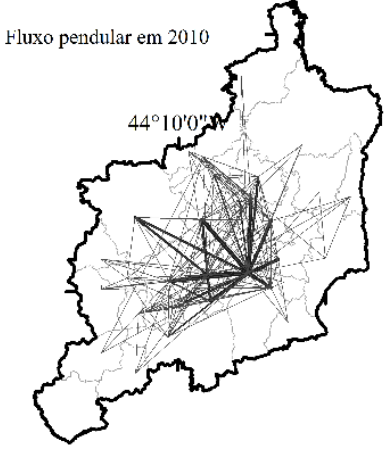

Pendulares recebidos

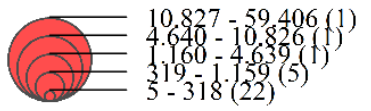

Fonte: Elaboração própria. Questionário da Amostra, IBGE 2010 


\section{CONSIDERAÇÕES FINAIS}

As taxas médias geométricas de crescimento anual da região sugerem que a RMBH vem sofrendo efeitos da desconcentração já que ao analisar o crescimento urbano da região desde a década de 70 nos deparamos com níveis elevados de crescimento demográfico para além de Belo Horizonte. Indicando-se assim uma tendência da RMBH se consolidar como uma região polinucleada. Mas também com traços de segregação socioespacial já que tal crescimento se dá em grande medida pela saturação dos municípios mais centrais em termos residenciais, o aumento do preço do solo e o investimento em políticas públicas de habitação que vêm, nos últimos anos afastando a população mais pobre dos centros econômicos-funcionais (OJIMA; MARANDOLA JR; 2012; DINIZ, 2017).

Os resultados da análise da migração e dos movimentos pendulares conjuntamente, evidenciaram quantitativamente a disparidade visualizada na dinâmica metropolitana, pois tanto os deslocamentos relacionados a zona sul, quanto os deslocamentos em massa em direção ao eixo oeste e norte central são estimulados pela questão da moradia. Mas por se tratar de padrões construtivos e níveis de urbanização diferenciados produzem volumes distintos em termos de fluxos migratórios e movimentos pendulares.

$\mathrm{Na} \mathrm{RMBH}$, a população de Ribeirão das Neves aparece como a população que mais se desloca, tanto em termos residenciais, com fluxos direcionados para as franjas metropolitanas, como em termos da mobilidade por motivo de trabalho, em direção à metrópole. A metrópole belo-horizontina é atrativa para trabalho e dependente da mão de obra da população de baixa renda e escolaridade média, embora esta se configure também como lócus de expulsão em detrimento da especulação imobiliária e do preço do solo - sendo responsável por $13 \%$ da população de emigrantes pendulares. Por outro lado, Nova Lima, mesmo que menos expressiva, responde por $3,3 \%$ dos emigrantes pendulares, emigrantes de alta renda que se deslocam por meio de transportes individuais e que habitam espaços homogêneos e mais segregados, verdadeiros enclaves, situados no Eixo Sul da RMBH.

Estes dados confirmam a força do setor imobiliário na RMBH. Desta forma, Belo Horizonte apresenta-se como uma metrópole, sendo sua centralidade pautada na oferta de bens e serviços, e não uma cidade industrial, deixando esse legado para Contagem. Por não possuir um passado de industrialização, o fator de expulsão de Belo Horizonte está muito mais associado ao valor do solo do que ao desvinculamento geográfico dos indivíduos migrantes em relação ao local de trabalho. O que significa que a maioria das pessoas que residiam em Belo Horizonte saíram da capital por não conseguir pagar pelo espaço de moradia.

Entretanto, não só de situações extremas é composta a realidade metropolitana. Constatou-se também que os municípios Contagem e Betim são produtores de acessibilidades e de mobilidades. Nestes municípios, as fixações das estruturas de atividades industriais são os principais produtores de fluxos, tanto para morar, quanto para trabalhar.

\section{AGRADECIMENTOS}

Agradecemos à Fundação de Amparo à Pesquisa do Estado de Minas Gerais (FAPEMIG) pela concessão da bolsa, recurso extremamente importante para o desenvolvimento deste artigo e de outros trabalhos durante o período do curso de mestrado, e atualmente do doutorado.

\section{REFERÊNCIAS}

BRITO, F.; SOUZA, J. DE. Expansão urbana nas grandes metrópoles: o significado das migrações intrametropolitanas e da mobilidade pendular na reprodução da pobreza. São Paulo em Perspectiva, v. 19, n. 4, p. 48-63, dez. 2005. Disponível em: $<$ http://www.scielo.br/scielo.php?script=sci arttext\&pid=S0102-88392005000400003\&lng=en\&nrm=iso > . Acesso em: 14. jul. 2019.

CANETTIERI, T. Uma nova segregação metropolitana: as periferias fractais - evidências encontradas na Região Metropolitana de Belo Horizonte. Revista Brasileira de Estudos Urbanos e Regionais, 2015. Disponível em: < https://rbeur.anpur.org.br/rbeur/article/view/4949/4686>. Acesso em: 14. jul. 2019.

CBO. Ministério do Trabalho. Classificação Brasileira de Ocupações Disponível em: < http://www.mtecbo.gov.br/cbosite/pages/informacoesGerais.jsf> A

\begin{tabular}{llllll}
\hline Caminhos de Geografia & Uberlândia & v. 22, n. 84 & dez/2021 & p. 154-168 & Página 167
\end{tabular}


CUNHA, J. M. P. DA. Retratos da mobilidade espacial no Brasil: os censos demográficos como fonte de dados. REMHU : Revista Interdisciplinar da Mobilidade Humana, v. 20, n. 39, p. 29-50, 2012. Disponível em: $\leq$ ttp://www.scielo.br/scielo.php?script=sci arttext\&pid=S198085852012000200003\&lng=en\&nrm=iso >. Acesso em: 14 jul. 2019.

DINIZ, G. L. Movimentos migratórios e pendulares por motivo de trabalho, da população residente nos municípios da região metropolitana de Belo Horizonte, a partir dos dados do censo demográfico de 2010. 2017. 93 f. Dissertação (Mestrado em Geografia). Programa de Pós-graduação em Geografia. Tratamento da Informação Espacial, PUC, Belo Horizonte, 2017. Disponível em: $<$ http://www.sistemas.pucminas.br/BDP/SilverStream/Pages/pg Consltem.html>. Acesso em: 04 abr. 2017.

; ALVIM, M. A. M. Mobilidade em rede: Análise da migração e do movimento pendular na Região Metropolitana de Belo Horizonte. 2019. Disponível em: <http://anpur.org.br/xviiienanpur/anaisadmin/capapdf.php?regid=1434>. Acesso em: 14 jul. 2019. GOTTDIENER, Mark. A produção social do espaço urbano. São Paulo: Edusp, 1997, 2a edição, 310 p. HALL, P..Cidades do amanhã: uma história intelectual do planejamento e do projeto urbanos no século XX. 4. ed. São Paulo - SP: Perspectiva, 2016.

LIMONAD, E.; SOARES DE MOURA COSTA, H. Cidade Excêntricas ou novas periferias? Revista Cidades, p. 27, 2015. Disponível em: <http://www.scielo.br/scielo.php?script=sci arttext\&pid=S198085852012000200003\&lng=en\&nrm=iso>. Acesso em: 14 jul. 2019.

LOBO, C. et al. Expanded commuting in the metropolitan region of Belo Horizonte: evidence for reverse commuting. Revista Brasileira de Estudos de População, v. 32, n. 2, p. 219-233, ago. 2015. Disponível em <http://www.scielo.br/scielo.php?script=sci arttext\&pid=S010230982015000200219\&lng=en\&nrm=iso $>$ Acesso em: 14 jul. 2019.

MOURA, R.; CASTELLO BRANCO, M. L. G.; FIRKOWSKI, O. L. C. DE F. Movimento pendular e perspectivas de pesquisas em aglomerados urbanos. São Paulo em Perspectiva, v. 19, n. 4, p. $121-$ 133, dez. 2005. Disponível em <http://www.scielo.br/scielo.php?script=sci arttext\&pid=S010288392005000400008\&lng=en\&nrm=iso >. Acesso em: 14 jul. 2019.

OJIMA, R.; MARANDOLA JR., E. Mobilidade populacional e um novo significado para as cidades: dispersão urbana e reflexiva na dinâmica regional não metropolitana. Revista Brasileira de Estudos Urbanos e Regionais, v. 14, n. 2, p. 103, 2012. Disponível em <https://rbeur.anpur.org.br/rbeur/article/view/4104/4002> Acesso em: 14 jul. 2019.

et al. $\mathrm{O}$ estigma de morar longe da cidade: repensando o consenso sobre as "cidadesdormitório" no Brasil. Cadernos Metrópole, [S.I.], v. 12, n. 24, maio 2011. ISSN2236-9996. Disponível em:<https://revistas.pucsp.br/index.php/metropole/article/view/5896>. Acesso em: 26 maio 2017. doi:http://dx.doi.org/10.1590/5896.

PINHO, B. A. T. D. DE; ROCHA, A. S.; BRITO, F. A mobilidade pendular dos trabalhadores: uma análise do mercado de trabalho na RMBH. Anais do XIX Encontro Nacional de Estudos Populacionais, v. 0, n. 0, p. 1-19, 2014. Disponível em <abep.org.br/publicacoes/index.php/anais/article/view/2156/2111> Acesso em: 14 jul. 2019.

SOARES DE MOURA COSTA., H. A expansão metropolitana de Belo Horizonte: dinâmica e especificidades no eixo-sul: developing the ecosystem approach to drive positive urban transformations in the context of intersecting vulnerabilities View project Sustainable urbanisation and environmental conflicts View project. [s.I: s.n.]. Disponível em: $<$ https://www.researchgate.net/publication/277202628>. Acesso em: 14 jul. 2019.

H. et al. Novas periferias metropolitanas: a expansão metropolitana em Belo Horizonte: dinâmica e especificidades no eixo sul. [s.l.] C/Arte, 2006.

VILLAÇA, F. Espaço intra-urbano no Brasil. São Paulo: Studio Nobel, FAPESP. Lincoln Institute, 1998.

Recebido em: 21/08/2020

Aceito para publicação em: 29/12/2020 